\title{
Indução do amadurecimento de peras 'Rocha' submetidas à baixa temperatura e à aplicação de etileno
}

\author{
Mariuccia Schlichting de Martin ${ }^{(1)}$, Cristiano André Steffens ${ }^{(1)}$, Cassandro Vidal Talamini do Amarante ${ }^{(1)}$, \\ Marcos Vinicius Hendges ${ }^{(1)}$, Lucimara Rogéria Antoniolli ${ }^{(2)}$ e Vinicio Denardi ${ }^{(1)}$
}

(1)Universidade do Estado de Santa Catarina, Centro de Ciências Agroveterinárias, Avenida Luiz de Camões, no 2090 , CEP 88520-000 Lages, SC, Brasil. E-mail: mariucciasdm@hotmail.com, cristiano.steffens@udesc.br, cassandro.amarante@udesc.br, marcos_hendges@hotmail.com, vinidenardi17@gmail.com (2)Embrapa Uva e Vinho, Rua Livramento, no 515, CEP 95700-000 Bento Gonçalves, RS, Brasil. E-mail: lucimara.antoniolli@embrapa.br

Resumo - O objetivo deste trabalho foi avaliar o efeito da exposição ao frio e da aplicação de etileno, em diferentes períodos, sobre o amadurecimento e a qualidade de peras 'Rocha'. Foram conduzidos dois experimentos. No experimento 1 , foram avaliados quatro períodos de exposição a $3^{\circ} \mathrm{C}(0,14,28$ e 42 dias) e o efeito da aplicação de $100 \mathrm{ppm}$ de $\mathrm{C}_{2} \mathrm{H}_{4}$ por um e dois dias. No experimento 2 , foram testados cinco períodos de exposição a $3^{\circ} \mathrm{C}(0,15,30,45$ e 60 dias $)$. No experimento 1 , o aumento do período de frio de 14 para 28 dias ocasionou maior amarelecimento da casca e aumento das taxas respiratória e de produção de etileno. Em todos os tratamentos, os frutos apresentaram menor firmeza de polpa e de força para penetração da polpa, em comparação ao controle; no entanto, apresentaram textura adequada para consumo após sete dias em condição ambiente. No experimento 2 , a firmeza de polpa, a força para penetração da polpa, a cor verde da casca e a acidez titulável diminuiram com o aumento do período de frio. A exposição dos frutos ao frio de $3^{\circ} \mathrm{C}$, por 15 dias, e a aplicação de 100 ppm de $\mathrm{C}_{2} \mathrm{H}_{4}$, por dois dias, são indicadas para induzir o amadurecimento de peras 'Rocha'.

Termos para indexação: Pyrus communis, exposição ao frio, firmeza de polpa, pós-colheita, textura.

\section{Induction of ripening in 'Rocha' pears subjected to low-temperature and ethylene application}

\begin{abstract}
The objective of this work was to evaluate the effect of the exposure to low-temperature and the application of ethylene, in different periods, on the ripening and quality of 'Rocha' pears. Two experiments were carried out. In experiment 1 , four periods of exposure to $3^{\circ} \mathrm{C}(0,14,28$, and 42 days) and the effect of the application of $100 \mathrm{ppm}$ of $\mathrm{C}_{2} \mathrm{H}_{4}$ for one and two days were evaluated. In experiment 2 , five periods of exposure to $3^{\circ} \mathrm{C}$ were tested $(0,15,30,45$, and 60 days). In experiment 1 , increasing the period of low-temperature from 14 to 28 days brought about more yellowing to skin and increased respiratory rates and ethylene production. In all treatments, fruit had lower pulp firmness and lower strength to resist pulp penetration, in comparison to the control treatment; however, they showed buttery texture after seven days under environment conditions. In experiment 2, flesh firmness, strength to penetrate pulp, green skin, and titratable acidity decreased with the increase of the period under low-temperature. Fruit exposure to low-temperature at $3^{\circ} \mathrm{C}$, for 15 days, and the application of $100 \mathrm{ppm}$ of $\mathrm{C}_{2} \mathrm{H}_{4}$, for two days, are indicated to induce ripening in 'Rocha' pears.
\end{abstract}

Index terms: Pyrus communis, low-temperature conditioning, flesh firmness, postharvest, texture.

\section{Introdução}

A pera 'Rocha' é uma cultivar europeia (Pyrus communis) que apresenta boas características organolépticas e boa aceitação comercial. Assim como as demais cultivares europeias, a pera 'Rocha' não é capaz de atingir qualidade própria para o consumo ainda na planta, por isso, determinados tratamentos são necessários no período pós-colheita, para completar o processo de amadurecimento (Villalobos-Acuña \& Mitcham, 2008; Sugar \& Basile, 2009).

A pera europeia, quando comercializada logo após a colheita, não apresenta amadurecimento adequado e é incapaz de desenvolver textura e sabor apropriados para o consumo (Makkumrai et al., 2014). Assim, a maturação ideal para a colheita da pera 'Rocha' é definida como o ponto a partir do qual o fruto é capaz de evoluir para uma qualidade ideal de consumo, quando 
fornecidas as condições pós-colheita apropriadas, como exposição ao frio, a temperaturas que podem variar de -1 a $10^{\circ} \mathrm{C}$, e aplicação de etileno $\left(\mathrm{C}_{2} \mathrm{H}_{4}\right)$ aos frutos, seguidas por um número variável de dias à temperatura ambiente (Sugar \& Basile, 2009, 2013).

Durante a exposição à baixa temperatura, as peras desenvolvem a capacidade de produzir etileno a uma taxa suficiente para ativar e completar o processo de amadurecimento (Villalobos-Acuña \& Mitcham, 2008). O tempo necessário de exposição ao frio varia conforme a cultivar e depende também do estádio de maturação em que o fruto foi colhido, do local de crescimento dos frutos e da temperatura utilizada no processo (Sugar \& Basile, 2006; Villalobos-Acuña \& Mitcham, 2008; Sugar \& Einhorn, 2011).

Para as peras 'Comice' e 'Bosc', colhidas durante a maturação comercial, são necessários 30 e 15 dias, respectivamente, em condições de frio a $-1^{\circ} \mathrm{C}$, para induzir o amadurecimento dos frutos e permitir que atinjam a textura adequada para o consumo (Sugar \& Basile, 2009). Para peras 'Packham's Triumph', colhidas com firmeza de polpa de $72 \mathrm{~N}$, o tempo mínimo é de 20 dias, em condições de frio a $-1^{\circ} \mathrm{C}$, para induzir o amadurecimento (Seibert et al., 2000). De acordo com Fonseca et al. (2005), após 60 dias de armazenamento a $0^{\circ} \mathrm{C}$, peras 'Rocha' produzidas no Oeste de Portugal apresentaram amadurecimento normal e uniforme, produziram aroma característico e desenvolveram textura adequada para o consumo.

A redução do período de frio requerido para induzir o amadurecimento é desejável, uma vez que permite aos produtores disponibilizar o produto mais rapidamente no mercado, além de reduzir os custos de produção. Alguns autores verificaram que a utilização de temperaturas intermediárias no processo, como de $5^{\circ} \mathrm{C}$ ou $10^{\circ} \mathrm{C}$, induz peras 'd'Anjou' e 'Bartlett' a produzir etileno mais rapidamente do que a $0^{\circ} \mathrm{C}$ ou a temperaturas inferiores (Villalobos-Acuña \& Mitcham, 2008; Sugar \& Basile, 2013). Ao trabalhar com peras 'd'Anjou', colhidas com firmeza de polpa de 66 N, Sugar \& Einhorn (2011) verificaram que o período ideal de frio a $-0,5^{\circ} \mathrm{C}$ foi de 60 dias, enquanto a $5^{\circ} \mathrm{C}$ o período de frio foi reduzido para 30 dias. Apesar de esses antecedentes terem mostrado resultados promissores, não se encontraram estudos que avaliem temperaturas superiores a $0^{\circ} \mathrm{C}$ para indução do amadurecimento de peras 'Rocha'.
A aplicação de etileno também pode ser utilizada comercialmente para induzir o amadurecimento de peras europeias. Em 'd'Anjou', 'Bartlett' e 'Conference', a aplicação de etileno após a colheita ativa o amadurecimento, proporcionando frutos com textura amanteigada e aroma característico (Chiriboga et al., 2011). Em peras 'Rocha', Fonseca et al. (2005) observaram que a aplicação de $100 \mathrm{ppm}$ de $\mathrm{C}_{2} \mathrm{H}_{4}$ induziu o amadurecimento dos frutos e conferiu textura adequada para o consumo, após exposição à temperatura ambiente. Contudo, a eficiência da indução do amadurecimento também irá depender do período de exposição dos frutos ao etileno (Sugar \& Basile, 2013).

Para peras 'Rocha' produzidas na Região Sul do Brasil, até o momento, não há informações em relação aos melhores métodos para indução do amadurecimento dos frutos.

O objetivo deste trabalho foi avaliar o efeito da exposição ao frio de $3^{\circ} \mathrm{C}$ e da aplicação de etileno, em diferentes períodos, sobre o amadurecimento e qualidade de peras 'Rocha'.

\section{Material e Métodos}

Dois experimentos foram conduzidos com peras 'Rocha', provenientes de um pomar comercial localizado no Município de Vacaria, RS (2830'39"S, $50^{\circ} 55^{\prime} 47^{\prime \prime} \mathrm{W}$, a $960 \mathrm{~m}$ de altitude). O primeiro experimento foi realizado na safra 2010/2011 e o segundo na safra 2012/2013, com frutos coletados durante a colheita comercial, com firmeza de polpa entre 65 e $55 \mathrm{~N}$, conforme recomendado para a cultivar Rocha (Cavaco et al., 2009). Após a colheita, foram realizadas a seleção dos frutos e a homogeneização das amostras experimentais, e os frutos com podridões, lesões, defeitos ou de baixo calibre foram eliminados.

No primeiro experimento, conduzido com frutos produzidos no ano agrícola 2010/2011, avaliou-se o efeito do frio e da aplicação de etileno na indução do amadurecimento, nos seguintes tratamentos: 0 (controle), 14, 28 e 42 dias de exposição ao frio de $3,0 \pm 0,5^{\circ} \mathrm{C}$ (temperatura do ar no interior da câmara), aplicação de 100 ppm de $\mathrm{C}_{2} \mathrm{H}_{4}$ por um dia, e aplicação de 100 ppm de $\mathrm{C}_{2} \mathrm{H}_{4}$ por dois dias. Aplicou-se $\mathrm{C}_{2} \mathrm{H}_{4}$ aos frutos à temperatura ambiente $\left(20 \pm 5^{\circ} \mathrm{C}\right)$, tendose retirado o gás de um cilindro pressurizado com o auxílio de uma seringa e injetado no interior de uma 
minicâmara hermética. Ao final da aplicação dos tratamentos, os frutos foram mantidos durante sete dias à temperatura ambiente $\left(20 \pm 5^{\circ} \mathrm{C}\right)$, para simular $\mathrm{o}$ período de comercialização.

No segundo experimento, que foi realizado com frutos produzidos no ano agrícola 2012/2013, apenas o efeito do frio foi avaliado, e os tratamentos constituíram-se de cinco períodos $-0,15,30,45$ e 60 dias de armazenamento, à temperatura de $3,0 \pm 0,5^{\circ} \mathrm{C}$.

Para as análises de qualidade, no experimento 1, avaliaram-se os frutos diariamente quanto aos atributos de taxas respiratória e de produção de etileno e cor da casca. No sétimo dia, realizaram-se as avaliações de firmeza de polpa, atributos de textura, acidez titulável (AT) e teor de sólidos solúveis (SS). No experimento 2, as análises foram realizadas ao final do período de exposição ao frio e após sete dias de exposição à temperatura ambiente, quanto à cor da casca, firmeza de polpa, atributos de textura, AT e teor de SS.

As taxas respiratória ( $\mathrm{nmol}$ de $\mathrm{CO}_{2} \mathrm{~kg}^{-1} \mathrm{~s}^{-1}$ ) e de produção de etileno ( $\mathrm{nmol}$ de $\mathrm{C}_{2} \mathrm{H}_{4} \mathrm{~kg}^{-1} \mathrm{~s}^{-1}$ ) foram quantificadas após colocação dos frutos de cada amostra em um recipiente de plástico com volume de $4.100 \mathrm{~mL}$, com fechamento hermético. As taxas respiratórias e de produção de etileno foram obtidas pela diferença da concentração de $\mathrm{CO}_{2}$ e de $\mathrm{C}_{2} \mathrm{H}_{4}$, respectivamente, no interior do recipiente, imediatamente após o seu fechamento e depois de uma hora. Alíquotas de gás $(1 \mathrm{~mL})$ foram retiradas dos recipientes através de um septo de borracha e injetadas em um cromatógrafo a gás, modelo CP-3800 (Varian, Palo Alto, CA, EUA), equipado com uma coluna Porapak $\mathrm{N}$ de $3 \mathrm{~m}$ de comprimento (80-100 mesh), metanador e detector de ionização de chama. As temperaturas da coluna, do detector, do metanador e do injetor foram de 45 , 120,380 e $110^{\circ} \mathrm{C}$, respectivamente. Os fluxos de nitrogênio, hidrogênio e ar sintético foram de 70, 30 e $300 \mathrm{~mL} \mathrm{~min}^{-1}$, respectivamente.

A determinação da cor da casca (ângulo hue, $h^{\circ}$ ) foi efetuada com um colorímetro modelo CR 400 (Konica Minolta, Tóquio, Japão). As leituras foram realizadas na região equatorial dos frutos. $\mathrm{O} \mathrm{h}^{\circ}$ define a coloração básica, em que: $0^{\circ}$ é a vermelha, $90^{\circ}$ é a amarela e $180^{\circ}$ é a verde.

A firmeza de polpa $(\mathrm{N})$ foi determinada na região equatorial dos frutos, em dois pontos opostos, após remoção de uma pequena porção da casca, com o auxílio de um penetrômetro eletrônico (GÜSS Manufacturing
Ltd., Cidade do Cabo, África do Sul), equipado com ponteira de 7,9 mm de diâmetro.

Os atributos de textura $(\mathrm{N})$ foram analisados com um texturômetro eletrônico TAXT-plus (Stable Micro Systems Ltd., Surrey, Reino Unido), tendo-se avaliado as forças necessárias para o rompimento da casca e para a penetração na polpa, por meio de ponteira modelo PS2 com $2 \mathrm{~mm}$ de diâmetro, a qual foi introduzida na polpa à profundidade de $10 \mathrm{~mm}$, com velocidades pré-teste, teste e pós-teste de 30,3 e $40 \mathrm{~mm} \mathrm{~s}^{-1}$, respectivamente.

Os valores de AT (percentagem de ácido málico) foram determinados em uma amostra de $10 \mathrm{~mL}$ de suco, extraído de fatias retiradas da porção distal dos frutos, com o auxílio de uma centrífuga. Essa amostra foi diluída em $90 \mathrm{~mL}$ de água destilada e titulada com solução de $\mathrm{NaOH}$ a $0,1 \mathrm{~N}$ até $\mathrm{pH} 8,1$. Para a titulação, utilizou-se titulador automático TitroLine easy (Schott Instruments, Mainz, Rheinland-Pfalz, Alemanha).

Os teores de SS ( ${ }^{\circ}$ Brix) foram obtidos por refratometria, em uma alíquota do suco extraído para a quantificação de AT. Para as determinações, utilizou-se refratômetro digital modelo PR201 $\alpha$ (Atago, Tóquio, Japão).

Antes da aplicação dos tratamentos, quatro amostras de 15 frutos foram avaliadas para determinação da qualidade inicial das peras, que apresentaram, para os experimentos 1 e 2 , respectivamente, firmeza de polpa de 62,4 e 59,2 N, teor de sólidos solúveis de 10,0 e $11,5^{\circ}$ Brix e acidez titulável de 0,29 e $0,24 \%$ de ácido málico.

Utilizou-se o delineamento experimental inteiramente casualizado, com quatro repetições e unidade experimental constituída por 30 frutos. No experimento 1 , os dados foram submetidos à análise de variância, e as médias dos tratamentos foram comparadas pelo teste de Tukey a $5 \%$ de probabilidade. No experimento 2, as médias foram submetidas à análise de regressão. Para estes procedimentos, utilizou-se o programa estatístico SAS (SAS Institute, Cary, NC, EUA).

\section{Resultados e Discussão}

Os resultados obtidos no experimento 1, Figura 1 A, mostram que a taxa de produção de etileno se manteve mais elevada nos frutos submetidos a 28 dias de exposição ao frio, em comparação ao controle, aos frutos tratados com $\mathrm{C}_{2} \mathrm{H}_{4}$ e aos frutos submetidos ao frio 


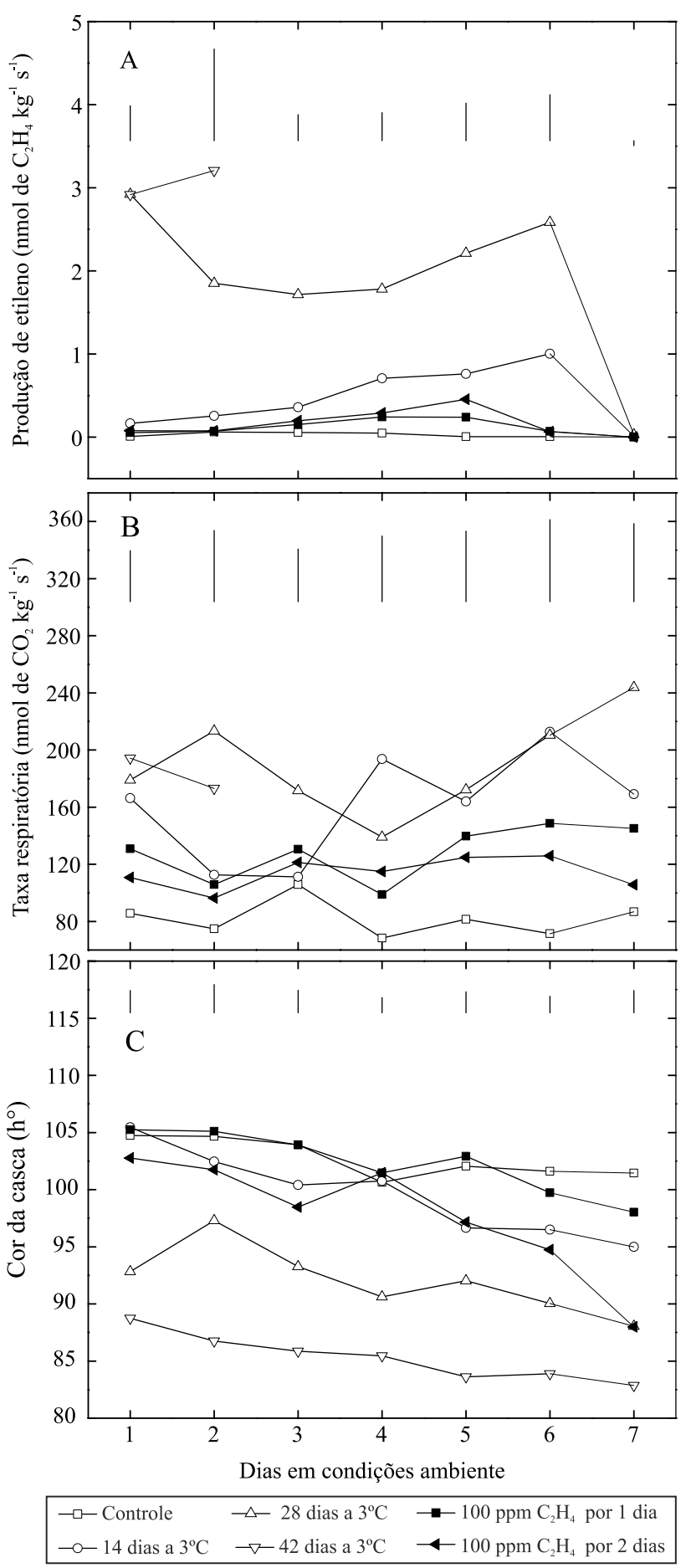

Figura 1. Experimento 1: taxa de produção de etileno (A), taxa respiratória (B) e cor da casca (C) de peras 'Rocha', submetidas a diferentes períodos de exposição ao etileno e ao frio $\left(3^{\circ} \mathrm{C}\right)$, avaliadas durante sete dias em condição ambiente. As barras verticais no interior de cada gráfico representam as diferenças mínimas significativas entre tratamentos, calculadas pelo teste de Tukey, a 5\% de probabilidade. por 14 dias. $\mathrm{O}$ aumento do período de frio incrementou a taxa de produção de etileno, e o tratamento de 28 dias apresentou maior produção do que o de 14 dias, durante todo o período de avaliação. O pico de produção de etileno foi evidente nos frutos dos tratamentos de 14 e 28 dias de exposição ao frio e ocorreu aos seis dias, à temperatura ambiente, tendo sido mais elevado nos frutos expostos a 28 dias de frio $(2,59 \mathrm{nmol}$ de $\left.\mathrm{C}_{2} \mathrm{H}_{4} \mathrm{~kg}^{-1} \mathrm{~s}^{-1}\right)$ em relação àqueles expostos a 14 dias (1,0 nmol de $\left.\mathrm{C}_{2} \mathrm{H}_{4} \mathrm{~kg}^{-1} \mathrm{~s}^{-1}\right)$. À medida que o tempo de exposição ao frio é estendido, tende a ocorrer o aumento e a antecipação do pico de produção de etileno, após a transferência dos frutos para a condição de temperatura ambiente (Seibert et al., 2000).

Verificou-se que os valores da produção de etileno foram superiores nos frutos submetidos a 42 dias de frio (3,21 nmol de $\left.\mathrm{C}_{2} \mathrm{H}_{4} \mathrm{~kg}^{-1} \mathrm{~s}^{-1}\right)$, mas problemas técnicos impossibilitaram a avaliação desse atributo, após o segundo dia de manutenção à temperatura ambiente (Figura $1 \mathrm{~A}$, experimento 1). Segundo alguns autores (Agar et al., 2000; Villalobos-Acuña et al., 2011), a exposição de peras europeias a baixas temperaturas induz a formação das enzimas ACC oxidase e ACC sintase, ocasionando aumento da biossíntese de etileno e proporcionando o amadurecimento normal dos frutos, após exposição à temperatura ambiente.

Os frutos expostos ao frio por 14 dias apresentaram taxa de produção de etileno similar à do controle e aos frutos tratados com $\mathrm{C}_{2} \mathrm{H}_{4}$, tendo apresentado menor produção de etileno do que os frutos submetidos ao frio por 28 e 42 dias (Figura 1 A, experimento 1). A aplicação de $100 \mathrm{ppm}$ de $\mathrm{C}_{2} \mathrm{H}_{4}$ por 1 ou 2 dias não produziu efeito sobre a taxa de produção de etileno e proporcionou taxa de produção similar à do tratamento controle durante todo o período de avaliação. Fonseca et al. (2005) observaram que a atividade da ACC oxidase de peras aumentou com a exposição a 100 ppm de $\mathrm{C}_{2} \mathrm{H}_{4}$, mas que esse aumento foi menos pronunciado em relação a frutos que foram submetidos ao frio por 60 dias a $0^{\circ} \mathrm{C}$.

A taxa respiratória, de maneira geral, foi mais elevada nos frutos submetidos aos diferentes períodos de exposição ao frio $(14,28$ e 42 dias) do que nos demais tratamentos (controle e aplicação de 100 ppm de $\mathrm{C}_{2} \mathrm{H}_{4}$ por 1 ou 2 dias) (Figura $1 \mathrm{~B}$, experimento 1 ). $\mathrm{O}$ aumento do período de frio de 14 para 28 dias aumentou a taxa respiratória dos frutos na maior parte das avaliações. Esse comportamento é esperado, uma 
vez que o aumento da taxa respiratória é um evento secundário, estimulado pela maior taxa de produção de etileno durante o amadurecimento dos frutos (Figura 1 A, experimento 1). É importante observar que frutos que apresentam taxas respiratórias mais elevadas tendem a entrar em senescência mais cedo e a ter sua vida pós-colheita reduzida (Steffens et al., 2007).

$\mathrm{O}$ aumento do período de frio reduziu a coloração verde da casca dos frutos (menor $\mathrm{h}^{\mathrm{o}}$ ), quando estes foram transferidos para a condição ambiente, e proporcionou, no período de 42 dias, frutos mais amarelos do que os dos demais tratamentos, durante os sete dias de avaliação (Figura $1 \mathrm{C}$, experimento 1). É possível que a redução da cor verde nos frutos tenha ocorrido em razão da maior taxa de produção de etileno, uma vez que ela tendeu a aumentar com a extensão do período de exposição ao frio (Figura 1 A, experimento 1). A aplicação de $\mathrm{C}_{2} \mathrm{H}_{4}$ também proporcionou redução no $h^{\circ}$ dos frutos tratados durante dois dias, os quais apresentaram coloração similar à dos frutos submetidos ao frio por 28 dias. Entretanto, a aplicação de $100 \mathrm{ppm} \mathrm{de} \mathrm{C}_{2} \mathrm{H}_{4}$, por um dia, ocasionou aos frutos coloração semelhante à do controle até o sexto dia de avaliação, tendo diferido apenas no último dia, quando os frutos estavam menos verdes do que os frutos do controle e menos amarelos do que os frutos dos demais tratamentos. Esses resultados diferem dos encontrados por Dhillon \& Mahajan (2011), em peras 'Patharnakh', em que o tratamento dos frutos com 100 ppm de $\mathrm{C}_{2} \mathrm{H}_{4}$, por um dia, proporcionou frutos mais amarelos do que os do controle, aos quatro dias de exposição à temperatura ambiente. De acordo com os resultados obtidos por Coutinho et al. (2003), peras com coloração mais amarelada tendem a apresentar melhores notas em testes de comercialização simulada em relação a frutos mais verdes, o que mostra que o maior amarelecimento dos frutos, causado pelo aumento do tempo de exposição ao $\mathrm{C}_{2} \mathrm{H}_{4}$, pode ser vantajoso.

Em relação à firmeza de polpa, comparativamente ao controle, os demais tratamentos apresentaram menores valores, apesar de não terem diferido entre si, após sete dias de manutenção dos frutos em condição ambiente (Tabela 1, experimento 1). Assim, tanto os períodos de exposição ao frio (14, 28 e 42 dias) quanto a aplicação de $\mathrm{C}_{2} \mathrm{H}_{4}$ ( 1 e 2 dias) proporcionaram aos frutos uma alta taxa de perda de firmeza de polpa e propiciaram valores médios de firmeza inferiores a $23 \mathrm{~N}$, o mínimo exigido para que peras europeias apresentem textura adequada para o consumo (Calvo \& Sozzi, 2009). Segundo alguns autores, enzimas de parede celular, como as poligalacturonases (Hiwasa et al., 2004) e as $\beta$-galactosidases (Mwaniki et al., 2005) - responsáveis pelas modificações sofridas na textura de peras durante o amadurecimento - têm sua síntese induzida pelo etileno. Assim, são necessários tratamentos pós-colheita que induzem a produção de etileno, como a exposição dos frutos ao frio ou mesmo a aplicação de $\mathrm{C}_{2} \mathrm{H}_{4}$, para que os frutos percam firmeza de polpa e adquiram textura adequada para o consumo (Nashima et al., 2013).

Apesar de não ter ocasionado aumento expressivo na produção de etileno, o tratamento com 100 ppm de $\mathrm{C}_{2} \mathrm{H}_{4}$ por um ou dois dias foi eficiente em proporcionar a redução na firmeza de polpa dos frutos, após exposição à condição ambiente (Tabela 1, experimento 1). No entanto, para as peras 'Comice' e 'd'Anjou', Sugar \& Basile (2013) verificaram que a exposição a 100 ppm de $\mathrm{C}_{2} \mathrm{H}_{4}$, durante um ou dois dias, não foi suficiente para ocasionar reduções na firmeza de polpa com valores próprios para o consumo, após sete dias à temperatura ambiente. No entanto, para peras 'Bartlett', o tratamento com $100 \mathrm{ppm} \mathrm{de} \mathrm{C}_{2} \mathrm{H}_{4}$, durante dois dias, proporcionou aumento da taxa de produção de etileno e firmeza de polpa adequada para o consumo, após três dias em condição ambiente (Makkumrai et al., 2014). Estes resultados mostram que, possivelmente, o tempo de exposição ao $\mathrm{C}_{2} \mathrm{H}_{4}$ requerido para induzir o amadurecimento varia conforme a cultivar.

Os valores da força para ruptura da casca foram mais elevados no tratamento controle do que nos demais tratamentos (Tabela 1, experimento 1). Os períodos de exposição ao frio a $3^{\circ} \mathrm{C}$, de 28 e 42 dias, apresentaram a menor força requerida $(3,73$ e $3,61 \mathrm{~N}$, respectivamente), com valores superiores aos do tratamento de 14 dias de frio e também aos da aplicação de etileno. A força para ruptura da casca também foi reduzida pelo aumento do período de exposição dos frutos ao $\mathrm{C}_{2} \mathrm{H}_{4}$ de um $(6,51 \mathrm{~N})$ para dois $(4,91 \mathrm{~N})$ dias.

Tanto a aplicação de etileno quanto a exposição ao frio reduziram a força necessária para penetração da polpa dos frutos (Tabela 1, experimento 1). Apesar de não ter ocorrido diferença entre os períodos de frio quanto a esse atributo, no tratamento de 42 dias a $3^{\circ} \mathrm{C}$, os frutos apresentaram menor força para penetração da polpa comparativamente à aplicação de 100 ppm de $\mathrm{C}_{2} \mathrm{H}_{4}$ por um dia e, no entanto, não diferiram dos frutos 
da aplicação de etileno durante dois dias. De acordo com Fonseca et al. (2005), peras 'Rocha' submetidas ao frio de $0^{\circ}$, por 60 dias, perdem firmeza de polpa mais rapidamente do que aquelas tratadas durante um dia com $100 \mathrm{ppm}$ de $\mathrm{C}_{2} \mathrm{H}_{4}$ a $23^{\circ} \mathrm{C}$. De acordo com os mesmos autores, este resultado pode ser decorrente do maior incremento na atividade da ACC oxidase, nas peras submetidas a 60 dias de frio, do que naquelas tratadas com 100 ppm de $\mathrm{C}_{2} \mathrm{H}_{4}$.

A acidez titulável (AT) foi reduzida com a exposição das peras 'Rocha' ao frio, independentemente da duração da exposição, e com o tratamento de 100 ppm de $\mathrm{C}_{2} \mathrm{H}_{4}$ por dois dias (Tabela 1, experimento 1); todavia, o tratamento de 42 dias de exposição ao frio proporcionou menor AT aos frutos expostos do que o tratamento $\mathrm{C}_{2} \mathrm{H}_{4}$ por dois dias. Mesmo a baixas temperaturas, há continuidade da respiração dos frutos, o que leva a uma diminuição no conteúdo de ácidos orgânicos e, portanto, da AT. Não houve efeito da aplicação de etileno e da exposição ao frio sobre o teor de SS dos frutos (Tabela 1, experimento 1).

No experimento 2, observou-se redução da coloração verde da casca dos frutos com o aumento do período de exposição ao frio de 0 a 60 dias, tanto na saída da câmara quanto após sete dias em condição ambiente (Figura 2 A, experimento 2). Peras europeias tendem a sofrer uma redução significativa da coloração verde durante o processo de amadurecimento, e esse comportamento ocorre em consequência das clorofilases, que são enzimas induzidas pela ação do etileno, acompanhada pela síntese de carotenoides nos frutos (Coutinho et al., 2003; Predieri \& Gatti, 2009; Dhillon \& Mahajan, 2011).

A firmeza de polpa diminuiu com o aumento do tempo de exposição ao frio, conforme evidenciado na Figura 2 B (experimento 2). Na saída da câmara, a firmeza de polpa sofreu um pequeno decréscimo, pela exposição a até 45 dias de frio, e apresentou uma queda acentuada nos frutos expostos por 60 dias ao frio, os quais apresentaram valores médios de $28,4 \mathrm{~N}$. De acordo com Sugar \& Basile (2013), frutos que apresentam firmeza de polpa média inferior a $35,6 \mathrm{~N}$, imediatamente após o término do período de exposição ao frio, não são desejados, pois são muito suscetíveis ao dano mecânico no transporte e na comercialização.

$\mathrm{Na}$ avaliação realizada após sete dias, a firmeza de polpa também se reduziu com o aumento do tempo de exposição ao frio e apresentou redução substancial aos 15 dias de frio $(11,8 \mathrm{~N})$, em relação ao controle $(56,3 \mathrm{~N})$, o que mostra que esse período de armazenamento foi suficiente para proporcionar firmeza de polpa adequada para consumo (Calvo \& Sozzi, 2009). Outros autores também observaram redução na firmeza de polpa de peras 'Packham's' e 'd'Anjou', com o aumento do período de exposição ao frio (Seibert et al., 2000; Sugar \& Einhorn, 2011).

A força para ruptura da casca também diminuiu com o incremento no tempo de exposição ao frio (Figura 2 $\mathrm{C}$, experimento 2). Para a avaliação realizada após sete dias de manutenção dos frutos em condição ambiente, uma redução mais pronunciada ocorreu até 30 dias de exposição ao frio, e houve pouca variação após esse período.

Comportamento similar foi evidenciado entre a força para penetração da polpa e a firmeza de polpa, tanto na saída da câmara quanto após sete dias em condição ambiente (Figura $2 \mathrm{D}$, experimento 2). Após 15 dias de exposição ao frio, os frutos apresentaram redução bastante acentuada na força para penetração da polpa, o que mostrou que esse período foi suficiente

Tabela 1. Firmeza de polpa, forças para ruptura da casca e penetração da polpa, acidez titulável e teor de sólidos solúveis de peras 'Rocha', submetidas a diferentes períodos de exposição ao frio e ao etileno, avaliadas após sete dias em condição ambiente no experimento $1^{(1)}$.

\begin{tabular}{lccccc}
\hline Tratamento & $\begin{array}{c}\text { Firmeza de polpa } \\
(\mathrm{N})\end{array}$ & $\begin{array}{c}\text { Força para ruptura } \\
\text { da casca }(\mathrm{N})\end{array}$ & $\begin{array}{c}\text { Força para penetração } \\
\text { da polpa }(\mathrm{N})\end{array}$ & $\begin{array}{c}\text { Acidez titulável } \\
(\%)\end{array}$ & $\begin{array}{c}\text { Sólidos solúveis } \\
\left({ }^{\circ} \mathrm{Brix}\right)\end{array}$ \\
\hline Controle & $49,99 \mathrm{a}$ & $12,68 \mathrm{a}$ & $3,37 \mathrm{a}$ & $0,169 \mathrm{a}$ & $10,1 \mathrm{a}$ \\
14 dias a $3^{\circ} \mathrm{C}$ & $9,76 \mathrm{~b}$ & $5,13 \mathrm{c}$ & $0,75 \mathrm{bc}$ & $0,116 \mathrm{~cd}$ & $10,3 \mathrm{a}$ \\
28 dias a $3^{\circ} \mathrm{C}$ & $8,27 \mathrm{~b}$ & $3,73 \mathrm{~d}$ & $0,67 \mathrm{bc}$ & $0,101 \mathrm{~cd}$ & $11,0 \mathrm{a}$ \\
42 dias a $3^{\circ} \mathrm{C}$ & $6,55 \mathrm{~b}$ & $3,61 \mathrm{~d}$ & $0,49 \mathrm{c}$ & $0,090 \mathrm{~d}$ & $10,4 \mathrm{a}$ \\
$100 \mathrm{ppm} \mathrm{C}_{2} \mathrm{H}_{4} 1 \mathrm{dia}$ & $10,40 \mathrm{~b}$ & $6,51 \mathrm{~b}$ & $0,80 \mathrm{~b}$ & $0,154 \mathrm{ab}$ & $10,2 \mathrm{a}$ \\
$100 \mathrm{ppm} \mathrm{C}_{2} \mathrm{H}_{4} 2$ dias & $7,85 \mathrm{~b}$ & $4,91 \mathrm{c}$ & $0,54 \mathrm{bc}$ & $0,132 \mathrm{bc}$ & $10,3 \mathrm{a}$ \\
\hline $\mathrm{CV}(\%)$ & 20,7 & 6,3 & 11,4 & 12,0 & 6,0 \\
\hline
\end{tabular}

${ }^{(1)}$ Médias seguidas por letras iguais, nas colunas, não diferem entre si, pelo teste de Tukey, a 5\% de probabilidade. 

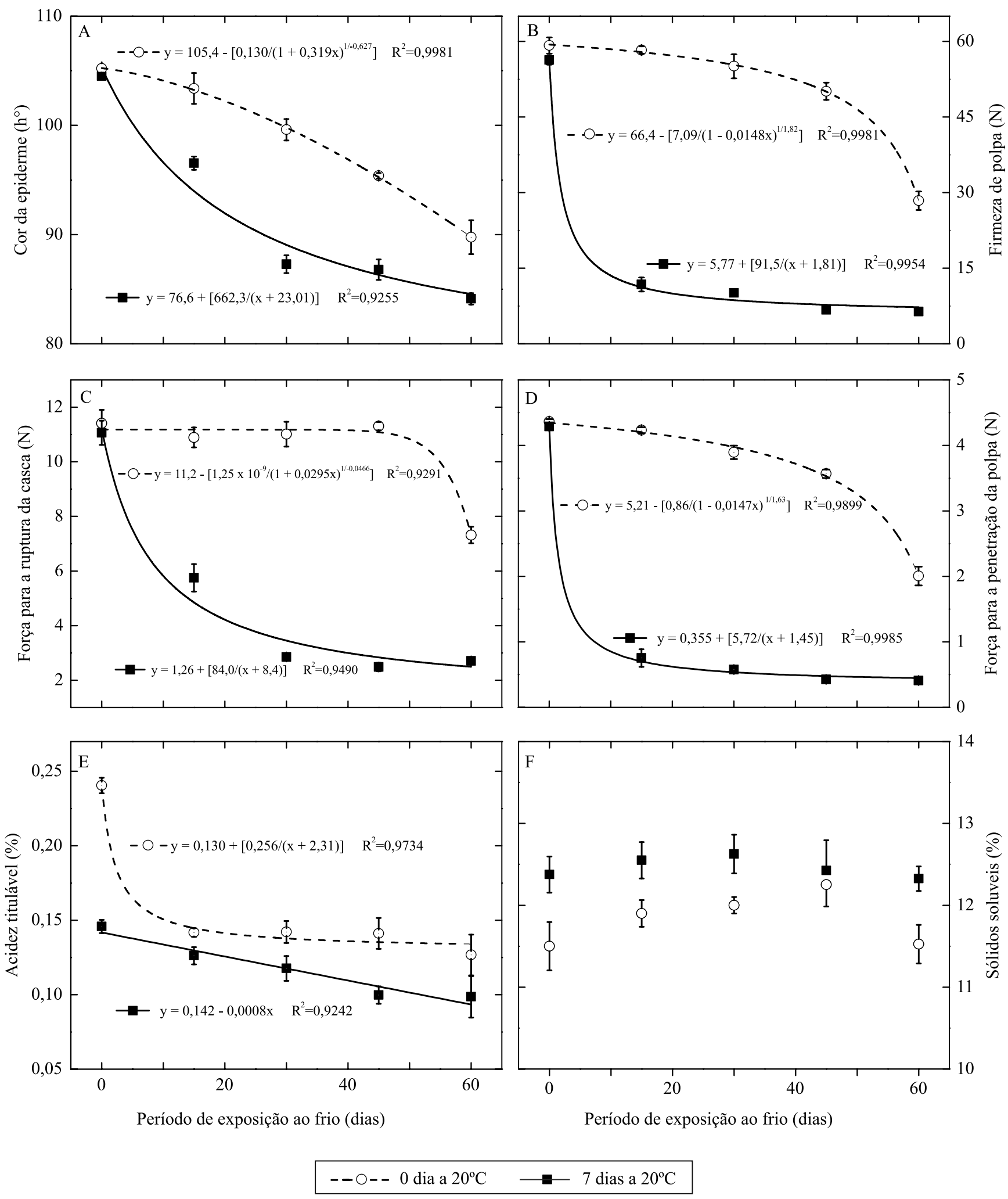

Figura 2. Experimento 2: cor da epiderme (A), firmeza de polpa (B), força para ruptura da casca (C), força para penetração da polpa (D), acidez titulável (E) e sólidos solúveis (F) de peras 'Rocha', à saída da câmara e após sete dias em condição ambiente, em função do período de exposição ao frio $\left(3^{\circ} \mathrm{C}\right)$. 
para ativar o processo de amadurecimento e ocasionar o desenvolvimento de firmeza de polpa adequada para o consumo. Para peras europeias, o desenvolvimento de uma textura caracterizada como amanteigada e suculenta é exigida pelos consumidores da maior parte do mundo (Villalobos-Acuña \& Mitcham, 2008; Makkumrai et al., 2014).

$\mathrm{Na}$ saída da câmara, os frutos apresentaram redução substancial na acidez titulável, aos 15 dias de exposição ao frio, em relação ao tratamento controle, e houve pouca variação com o incremento do tempo de exposição ao frio após esse período (Figura $2 \mathrm{E}$, experimento 2). $\mathrm{Na}$ avaliação realizada após sete dias, em condição ambiente, foi possível observar redução linear na AT com o incremento do tempo de frio. Esses resultados estão de acordo com aqueles obtidos por Elgar et al. (1997), em que os autores também observaram decréscimo da AT de peras 'Beurre Bosc' e 'Doyenne du Comice', com o aumento do período de exposição ao frio de duas para oito semanas.

O aumento do período de exposição ao frio não influenciou significativamente o conteúdo de SS nos frutos, tanto na saída da câmara quanto após sete dias em condição ambiente (Figura $2 \mathrm{~F}$, experimento 2). Para peras 'Rocha' produzidas em Portugal, a concentração de açúcares é considerada um fator-chave na qualidade comercial, uma vez que os consumidores tendem a apresentar preferência por frutos mais doces (Galvis-Sánchez et al., 2004). Todavia, de acordo com Predieri \& Gatti (2009), a relação entre o teor de SS e a aceitação comercial parece complexa, e esse parâmetro, isoladamente, não é capaz de predizer o nível de qualidade dos frutos.

Apesar de ser de 60 dias a $0^{\circ} \mathrm{C}$ o tempo e a temperatura de exposição ao frio (Fonseca et al., 2005) recomendados para peras 'Rocha' produzidas em Portugal, no presente estudo, foi possível constatar, com base nos resultados obtidos para firmeza de polpa, que o período de frio requerido para induzir o amadurecimento foi reduzido para 15 dias (Tabela 1, experimento 1; Figura $2 \mathrm{~B}$, experimento 2), quando utilizada a temperatura de $3^{\circ} \mathrm{C}$. Assim, o tempo de exposição ao frio pode ser reduzido, quando utilizadas temperaturas superiores a $0^{\circ} \mathrm{C}$, como as de 5 e $10^{\circ} \mathrm{C}$ (Sugar \& Einhorn, 2011; Sugar \& Basile, 2013), o que pode explicar o menor período de frio requerido no presente trabalho. Outro fator que pode ter contribuído para essa menor exigência de tempo de exposição ao frio é a localização do pomar, uma vez que as condições edafoclimáticas de Portugal diferem daquelas encontradas no Sul do Brasil.

Foi possível observar, pela análise dos resultados, que a exposição ao frio foi tão eficiente quanto a aplicação de $\mathrm{C}_{2} \mathrm{H}_{4}$ para induzir o amadurecimento. Esse resultado pode ser considerado vantajoso para as condições brasileiras de produção, pois o armazenamento refrigerado (exposição ao frio) consiste em uma técnica mais barata e difundida do que a aplicação de $\mathrm{C}_{2} \mathrm{H}_{4}$. Da mesma forma, é desejável a possibilidade de reduzir o período de frio requerido, para induzir o amadurecimento dos frutos, pois permite aos produtores reduzir o custo de produção, além de antecipar a comercialização dos frutos.

\section{Conclusões}

1. A exposição ao frio a $3^{\circ} \mathrm{C}$, por 15 dias, para frutos colhidos no estádio de maturação comercial, é suficiente para induzir o amadurecimento de peras 'Rocha' e proporcionar o desenvolvimento de firmeza de polpa adequada para o consumo.

2. A aplicação de $100 \mathrm{ppm}$ de $\mathrm{C}_{2} \mathrm{H}_{4}$, por dois dias, proporciona amadurecimento adequado de peras 'Rocha' e permite a redução do período necessário para adquirir firmeza de polpa adequada para consumo, em comparação à exposição ao frio.

\section{Agradecimentos}

À Coordenação de Aperfeiçoamento de Pessoal de Nível Superior (Capes), pela concessão da bolsa; ao Conselho Nacional de Desenvolvimento Científico e Tecnológico ( $\mathrm{CNPq})$, à Fundação de Amparo à Pesquisa e Inovação do Estado de Santa Catarina (Fapesc) e à Fundação Universidade do Estado de Santa Catarina (Udesc), pelo apoio financeiro.

\section{Referências}

AGAR, I.T.; BIASI, W.V.; MITCHAM, E.J. Cold storage duration influences ethylene biosynthesis and ripening of 'Bartlett' pears. HortScience, v.35, p.687-690, 2000.

CALVO, G.; SOZZI, G.O. Effectiveness of 1-MCP treatments on 'Bartlett' pears as influenced by the cooling method and the bin material. Postharvest Biology and Technology, v.51, p.49-55, 2009. DOI: 10.1016/j.postharvbio.2008.06.011.

CAVACO, A.M.; PINTO, P.; ANTUNES, M.D.; SILVA, J.M.; GUERRA, R. 'Rocha' pear firmness predicted by a Vis/NIR 
segmented model. Postharvest Biology and Technology, v.51, p.311-319, 2009. DOI: 10.1016/j.postharvbio.2008.08.013.

CHIRIBOGA, M.A.; SCHOTSMANS, W.C.; LARRIGAUDIÈRE, C.; DUPILlE, E.; RECASENS, I. How to prevent ripening blockage in 1-MCP-treated 'Conference' pears. Journal of the Science of Food and Agriculture, v.91, p.1781-1788, 2011. DOI: $10.1002 /$ jsfa.4382.

COUTINHO, E.F.; MALGARIM, M.B.; SOUZA, E.L. de; TREPTOW, R. de O. Qualidade pós-colheita da pêra (Pyrus communis L.) cultivar Carrick submetida a diferentes condições de armazenamento. Revista Brasileira de Fruticultura, v.25, p.417-420, 2003. DOI: 10.1590/S0100-29452003000300014.

DHILLON, W.S.; MAHAJAN, B.V.C. Ethylene and ethephon induced fruit ripening in pear. Journal of Stored Products and Postharvest Research, v.2, p.45-51, 2011.

ELGAR, H.J.; WATKINS, C.B.; MURRAY, S.H.; GUNSON, A. Quality of 'Beurre Bosc' and 'Doyenne du Comice' pears in relation to harvest date and storage period. Postharvest Biology and Technology, v.10, p.29-37, 1997. DOI: 10.1016/ S0925-5214(96)00058-0.

FONSECA, S.; MONTEIRO, L.; BARREIRO, M.G.; PAIS, M.S. Expression of genes encoding cell wall modifying enzymes is induced by cold storage and reflects changes in pear fruit texture. Journal of Experimental Botany, v.56, p.2029-2036, 2005. DOI: $10.1093 /$ jxb/eri201.

GALVIS-SÁNCHEZ, A.C.; FONSECA, S.C.; MORAIS, A.M.M.B.; MALCATA, F.X. Sensorial and physicochemical quality responses of pears (cv. Rocha) to long-term storage under controlled atmospheres. Journal of the Science of Food and Agriculture, v.84, p.1646-1656, 2004. DOI: 10.1002/jsfa.1798.

HIWASA, K.; NAKANO, R.; HASHIMOTO, A.; MATSUZAKI, M.; MURAYAMA, H.; INABA, A.; KUBO, Y. European, Chinese and Japanese pear fruits exhibit differential softening characteristics during ripening. Journal of Experimental Botany, v.55, p.2281-2290, 2004. DOI: 10.1093/jxb/erh250.

MAKKUMRAI, W.; ANTHON, G.E.; SIVERTSEN, H.; EBELER, S.E.; NEGRE-ZAKHAROV, F.; BARRETT, D.M.; MITCHAM, E.J. Effect of ethylene and temperature conditioning on sensory attributes and chemical composition of 'Bartlett' pears. Postharvest Biology and Technology, v.97, p.44-61, 2014. DOI: 10.1016/j. postharvbio.2014.06.001.

MWANIKI, M.W.; MATHOOKO, F.M.; MATSUZAKI, M.; HIWASA, K.; TATEISHI, A.; USHIJIMA, K.; NAKANO, R.; INABA, A.; KUBO, Y. Expression characteristics of seven members of the $\beta$-galactosidase gene family in 'La France' pear (Pyrus communis L.) fruit during growth and their regulation by 1-methylcyclopropene during postharvest ripening. Postharvest
Biology and Technology, v.36, p.253-263, 2005. DOI: 10.1016/j. postharvbio.2005.02.002.

NASHIMA, K.; SHIMIZU, T.; NISHITANI, C.; YAMAMOTO, T.; TAKAHASHI, H.; NAKAZONO, M.; ITAI, A.; ISUZUGAWA, K.; HANADA, T.; TAKASHINA, T.; MATSUMOTO, S.; OTAGAKI, S.; OIKAWA, A.; SHIRATAKE, K. Microarray analysis of gene expression patterns during fruit development in European pear (Pyrus communis). Scientia Horticulturae, v.164, p.466-473, 2013. DOI: 10.1016/j.scienta.2013.09.054.

PREDIERI, S.; GATTI, E. Effects of cold storage and shelf-life on sensory quality and consumer acceptance of 'Abate Fetel' pears. Postharvest Biology and Technology, v.51, p.342-348, 2009. DOI: 10.1016/j.postharvbio.2008.09.006.

SEIBERT, E.; BARRADAS, C.I.N.; ARAÚJO, P.J. de; BENDER, R.J. Efeito do ethephon e da frigoconservação na maturação de peras cv. 'Packham's Triumph'. Pesquisa Agropecuária Brasileira, v.35, p.55-62, 2000. DOI: 10.1590/S0100-204X2000000100008.

STEFFENS, C.A.; BRACKMANN, A.; PINTO, J.A.V.; EISERMANN, A.C. Taxa respiratória de frutas de clima temperado. Pesquisa Agropecuária Brasileira, v.42, p.313-321, 2007. DOI: 10.1590/S0100-204X2007000300003.

SUGAR, D.; BASILE, S.R. Ethylene treatment promotes early ripening capacity in mature 'Comice' pears. HortTechnology, v.16, p.89-91, 2006.

SUGAR, D.; BASILE, S.R. Integrated ethylene and temperature conditioning for induction of ripening capacity in 'Anjou' and 'Comice' pears. Postharvest Biology and Technology, v.83, p.9-16, 2013. DOI: 10.1016/j.postharvbio.2013.03.010.

SUGAR, D.; BASILE, S.R. Low-temperature induction of ripening capacity in 'Comice' and 'Bosc' pears as influenced by fruit maturity. Postharvest Biology and Technology, v.51, p.278-280, 2009. DOI: 10.1016/j.postharvbio.2008.07.003.

SUGAR, D.; EINHORN, T.C. Conditioning temperature and harvest maturity influence induction of ripening capacity in 'd'Anjou' pear fruit. Postharvest Biology and Technology, v.60, p.121-124, 2011. DOI: 10.1016/j.postharvbio.2010.12.005.

VILLALOBOS-ACUÑA, M.G.; BIASI, W.V.; FLORES, S.; JIANG, C.; REID; M.S.; WILLITS, N.H.; MITCHAM, E.J. Effect of maturity and cold storage on ethylene biosynthesis and ripening in 'Bartlett' pears treated after harvest with 1-MCP. Postharvest Biology and Technology, v.59, p.1-9, 2011. DOI: 10.1016/j. postharvbio.2010.08.001.

VILLALOBOS-ACUÑA, M.G.; MITCHAM, E.J. Ripening of European pears: the chilling dilemma. Postharvest Biology and Technology, v.49, p.187-200, 2008. DOI: 10.1016/j. postharvbio.2008.03.003.

Recebido em 6 de outubro de 2014 e aprovado em 2 de março de 2015 